\title{
The Menstrual Cycle Phases Are Like 'Body Seasons'
}

\author{
René Ecochard ${ }^{1,2,3 *}$, Marie Garmier-Billard ${ }^{1}$ and Jean Iwaz ${ }^{1,2,3}$ \\ ${ }^{1}$ Hospices Civils de Lyon, Service de Biostatistique-Bioinformatique, France \\ ${ }^{2}$ Université Lyon 1, France \\ ${ }^{3}$ Laboratoire de Biométrie et Biologie Évolutive, Équipe Biostatistique-Santé, France
}

\section{Introduction}

The time of human ecology comes as a natural fruit of the ecological movement [1]. We are seeing now a renewed interest in female physiology; particularly, in the female menstrual cycle. This desire has not been overridden, however, by the widespread use of hormonal contraception. Cycle monitoring applications for smart phones have now millions of users [2]. A better knowledge of the menstrual cycle may encourage women to appreciate its true value and preserve it rather than see it as an aggravation they must endure or treat.

Recent discoveries have shown that, for women, menstrual cycle phases are like 'body seasons' [3-6]. Beyond its role in fertility, which has been known for a long time, the female cycle affects the entire body with influences on woman's life and the lives of her family members, friends, and acquaintances $[3,7]$. Thus, cycle manipulation with hormonal contraception may not be longer considered totally safe [8,9].

Women have two assets whose importance goes beyond biological human life transmission: a) Femininity, that is the qualities or attributes traditionally regarded as characteristic of womanhood such as attention to details, sensitive towards other's feelings [10-12], and b) Motherhood, namely the qualities or attributes regarded as traditional characteristic of mothers, such as being protective, comforting, and others $[13,14]$. Initially grounded in the transmission of life, these two assets color the daily life of family and society through skills, abilities, experiences, and dynamism. These two assets shed light on human ecology (i.e., the living environment of each individual); they are expressed throughout the times of the female cycle.

In our article, we attempt by the mixed use of scientific language together side by side with sometimes an educational or even poetic language to suggest the anthropological implications of the field treated. Our aim is to show the importance of looking at the menstrual cycle with a philosophical point of view which usually has a medical and social component.

\section{The Three Stages of the Female Cycle}

The female cycle consists of three phases or stages: i) A waiting time, called latency: [15] ii) A fertility time, which is the time during which, if spouses have intercourse, man's sperm may reach the egg to fertilize it; and, iii) 'Child's time', the time when the conceived human life settles in the mother's womb. The woman's cycle allows this transmission of life.

Since the seventies, only the reproductive function of the female cycle has been valued. It then became common practice to manipulate the female cycle with the pill to avoid conception or try to suppress the discomfort associated with hormonal changes. Hormones used in contraceptives such as the pill or implants do not replace the natural hormones whose secretion they inhibit. More recently, suppressing the cycle has been proposed [16,17] as a means so women can have similar physiology to those of men and be able to compete for their professional careers.

At the same time, scientists have faced a conundrum: How can we understand why species selection has led to more than 300 cycles in a woman's life when only a few are enough for life transmission? Throughout species' evolution, the appearance and persistence of a given function is explained by an advantage for the concerned living organism. The persistence of so many cycles may therefore be considered favorable to the human species.

In addition, a large body of scientific research has indicated that women's aptitudes vary according to the time of the female cycle $[5,18,19]$. There are times associated with aptitudes for femininity and others with aptitudes for motherhood. The cycle allows not only life transmission but it also helps developing all women abilities.

\section{Without Cycle, a Woman Remains a Woman}

Young girls, young women, and older women remain

*Corresponding author: René Ecochard, Hospices Civils de Lyon, Pôle Santé Publique, Service de Biostatistique-Bioinformatique, Lyon, France

Accepted: September 05, 2019

Published online: September 07, 2019

Citation: Ecochard R, Garmier-Billard M, Iwaz J (2019) The Menstrual Cycle Phases Are Like 'Body Seasons'. Insights Anthropol 3(2):197-200 
women at any age. At each age, a specific hormonal climate helps women develop specific abilities. A woman remains a woman even when she does not have menstrual cycles and even when she takes a contraceptive. Indeed, each of her cells does carry two $X$ chromosomes that drive cell activity regardless of the hormonal climate. This is not the same for men whose cells carry $X$ and $Y$ chromosomes. In fact, each cell is 'sexed'.

Thus, suppressing the feminine cycle with contraception does not remove femininity. However, the change in the hormonal climate is not without consequences. As we will see below, under contraception, women no longer benefit from the help provided by hormonal balance.

\section{The Three Hormonal 'Climates' of the Cycle}

There are three distinct hormonal 'climates' during the female cycle [20]. These hormonal climates help the development of women's specific assets: Femininity and motherhood.

The first hormonal climate is seen during the latency period which begins with the onset of menses. At the beginning of each cycle, an increase in follicle-stimulating hormone levels causes follicular recruitment and development, followed several days later by secretion of estrogens. This is a time for hormonal rest; it is the 'winter' of the cycle. Just as during winter buds grow but do not open, ovarian follicles develop silently until one of them is selected [21]. Everything is quietly prepared without hormonal impregnation, namely, without high levels of estrogens and progesterone.

Then comes the 'spring' of the cycle when a follicle develops and ovulates. This follicle prepares the body by secreting a large amount of estrogens. This is the fertile period of the cycle during which intercourse may lead to conception. In fertile periods, under the effects of estrogens, femininity is 'festive'. The woman develops many aptitudes that are initially oriented towards fertility; but these aptitudes are beneficial for women's lives and society.

Finally, comes the third and last stage of the cycle, the post-ovulatory period, during which a second type of hormones, progesterone (progesterone: 'for' pregnancy), the maternity hormone, is added to estrogens. In the post-ovulatory period, women develop other aptitudes [22] than those of the previous period; precisely, those devoted to motherhood: Anticipation, interest in the future, etc. The body organizes itself to protect the future child. This is the moment the woman turns towards the 'nest'; she prepares and beautifies it. This is also the time she protects her 'territory' (like any 'mother' protects her offspring's environment) and during which she may become somewhat unpleasant. Then, other areas of interest may take over: The woman lives a time when she is invited to 'see further'; she appreciates taking a step back. Initially necessary to protect the conceived human being, these 'maternal' aptitudes are beneficial for personal, family, and social life.

Hormones make vital potentials reach their maximum: Just like the sun makes nature blossom with the sap that flows through plants, the female cycle makes femininity and motherhood blossom.

\section{Beauty Calls for Respect}

Modern biology is giving important places for beauty and vulnerability. These are the main incentives to step out of one's bubble and connect with others, which is essential for everyone's life and survival. Beauty, either plastic [23] or that of a person [24]; (especially the nobility of his/her acts) is very touching. This is the way we see the beauty of a child who invites us to take care of him or her or the beauty expressed by femininity or masculinity. However, this leads only to beauty and joy preservation-when desire is tamed to avoid possession that destroys human relationships. The beauty of the processes of life transmission is rooted in the female cycle; it calls for respect. The beauty of femininity that is magnified during the fertile period of the cycle is associated with the ability to transmit life. The sexual attraction of the fertile period is oriented towards conceiving a child. On the contrary, during the other two periods of the cycle, the sexual attraction is oriented towards conjugal dialogue and celebration of love. The fluctuation of the seasons of the cycle is thus an alternation of the two meanings of the intimate conjugal union: Transmission of life during fertile periods and celebration of spouses' union during non-fertile periods.

\section{Vulnerability Calls for Solidarity}

The second key element that biology has discovered as a condition for living in society is empathy: [25] a kind gesture toward vulnerable people; a so essential gesture that its biological mechanisms have been observed in 'low' animal species [26]. Just like beauty, vulnerability calls for empathy and becomes, therefore a value to preserve. Vulnerability should be recognized as great nobility. The female cycle is associated with vulnerability [27]. Welcoming the female cycle is to accept to leave room for uncertainty, for a certain degree of unpredictability.

Menses may interfere with a woman's social life. The man who is aware that menses mean the renewal of the womb's endometrium to welcome a child is invited to an attitude of sensitivity and admiration for the woman's ability to transmit life.

The fertile period is a special time for sexual attraction: Spouses have the chance to transmit life but must adapt their behavior to their project of welcoming (or not) a new child. If they choose to respect the female cycle, they will adapt the way they express their love to the rhythms of the woman's cycle and, in doing so, they will welcome together a kind of vulnerability that is so inherent to human life.

Thus, a couple and, more generally, a society that welcomes the female cycle with its irregularities and vulnerabilities is called to show empathy.

\section{Male Stability and the 'Seasons' of the Fe- male Cycle: A Beneficial Complementarity}

Once a couple has accepted the benefits of the 'seasons' of the female cycle, the stability of masculinity has to be accepted too as a necessary gift to establish a balance: Man's 
stability is beneficial for the couple. The man lives in a different 'climate' than the woman; the 'testosterone climate' which ensures stability together with adaptation to the environment [28]. Man's hormonal climate has no seasons; man's hormones are regulated to adapt to the needs of the moment. The amount of blood testosterone is high in the morning and low in the evening [29]. In the morning, a man is hormonally encouraged to leave his rest, step outdoors, and participate in the life of society. It has been shown that the amount of testosterone decreases in young fathers of children under 6 months of age; this makes these fathers more prone to take care of the child. In short, testosterone levels adapts to masculine and paternal needs [30,31].

Refusing to recognize the high value of masculinity prevents women and men from developing their potentials, their complementarity, and deprives their children from the sweetness of a family with fulfilled members. By developing his ability to take care of others, a man becomes a mature husband and father. This development requires that these places be granted to him by the woman. The female precious potentials can develop providing she recognizes she has an absolute need to be protected, loved, and admired by a man. Masculinity is a treasure of humankind; it should be preserved and, especially nowadays, further developed.

\section{Combining Modernity and Human Ecology}

Is it still possible to 'save' the female cycle? Is it possible for a woman to participate fully in public life (as she currently does for the good of society and her personal balance) while keeping her female cycle and welcoming its seasons? Everything we have mentioned above shows the importance of welcoming vulnerability and beauty of life as those of the female cycle. Nevertheless, it is also necessary to keep up with modernity. It is therefore a question of combining modernity and human ecology, of continuing to enrich society with masculine and feminine co-responsibility while preserving the potential of human ecology where masculinity and femininity develop their complementarity. For all this, it is essential to consider the female cycle as a treasure of humankind, simply because it is its starting point (the biological and human link that transmits life) and stands at the crossroads of spouses' love and the birth of their children. This calls today for a change in language on masculinity as well as on femininity.

Environmental ecology can only be promoted through a firm decision to change human behavior through considering the environment as a precious place that should be cared for. The same goes for human ecology: It will develop to serve human life only if appropriate lifestyle choices are made. For this, the cornerstone is the promotion of the respect of the times of the female cycle.

\section{References}

1. Hanley M (2016) Neglecting human ecology: The common element of global health failures. Linacre Q 83: 83-96.

2. Starling MS, Kandel Z, Haile L, et al. (2018) User profile and preferences infertility apps for preventing pregnancy: An exploratory pilot study. Mhealth 4: 21.
3. Sundström-Poromaa I (2018) The menstrual cycle influences emotion but has limited effect on cognitive function. Vitam Horm 107: 349-376.

4. Wong-Goodrich SJE, DeRosa HJ, Kee DW (2019) Dual-task paradigm reveals variation in left hemisphere involvement in verbal processing across the menstrual cycle in normally cycling women. Psychol Rep.

5. Casey E, Hameed F, Dhaher YY (2014) The muscle stretch reflex throughout the menstrual cycle. Med Sci Sports Exerc 46: 600609.

6. Sung ES, Kim JH (2019) The resistance training effects of different weight level during menstrual cycle in female. J Exerc Rehabil 15: 249-253.

7. Kiesner J (2017) The menstrual cycle-response and developmental affective-risk model: A multilevel and integrative model of influence. Psychol Rev 124: 215-244.

8. Lundin C, Danielsson KG, Bixo M, et al. (2017) Combined oral contraceptive use is associated with both improvement and worsening of mood in the different phases of the treatment cycle-A double-blind, placebo-controlled randomized trial. Psychoneuroendocrinology 76: 135-143.

9. Lundin C, Malmborg A, Slezak J, et al. (2018) Sexual function and combined oral contraceptives - a randomised, placebocontrolled trial. Endocr Connect.

10. Lithari C, Frantzidis CA, Papadelis C, et al. (2010) Are females more responsive to emotional stimuli? A neurophysiological study across arousal and valence dimensions. Brain Topogr 23: 27-40.

11. Proverbio AM, Zani A, Adorni R (2008) Neural markers of a greater female responsiveness to social stimuli. BMC Neurosci 9: 56.

12. Thayer J, Johnsen BH (2000) Sex differences in judgement of facial affect: A multivariate analysis of recognition errors. Scand J Psychol 41: 243-246.

13. Kinsley CH, Amory-Meyer E (2011) Why the maternal brain? J Neuroendocrinol 23: 974-983.

14. Nemsadze K, Silagava M (2010) Neuroendocrine foundation of maternal-child attachment. Georgian Med News 189: 21-26.

15. Ecochard R (2005) Heterogeneity, the masked part of reproductive technology success rates. Rev Epidemiol Sante Publique 53: 2S 107-117.

16. Strandjord SE, Rome ES (2015) Monthly periods--are they necessary? Pediatr Ann 44: e231-e236.

17. McMillan C, Jenkins A (2016) A magical little pill that will relieve you of your womanly issues": What young women say about menstrual suppression. Int J Qual Stud Health Well-being 11: 32932.

18. Konrad C, Engelien A, Schoning S, et al. (2008) The functional anatomy of semantic retrieval is influenced by gender, menstrual cycle, and sex hormones. J Neural Transm (Vienna) 115: 13271337.

19. Bayer J, Schultz H, Gamer M, et al. (2014) Menstrual-cycle dependent fluctuations in ovarian hormones affect emotional memory. Neurobiol Learn Mem 110: 55-63.

20. Del Rio JP, Alliende MI, Molina N, et al. (2018) Steroid hormones and their action in women's brains: The importance of hormonal balance. Front Public Health 6: 141. 
21. Gougeon A (2010) Human ovarian follicular development: From activation of resting follicles to preovulatory maturation. Ann Endocrinol (Paris) 71: 132-143.

22. Sundstrom Poromaa I, Gingnell M (2014) Menstrual cycle influence on cognitive function and emotion processing-from a reproductive perspective. Front Neurosci 8: 380.

23. Ishizu T, Zeki S (2011) Toward a brain-based theory of beauty. PLoS One 6: e21852.

24. Wang T, Mo L, Mo C, et al. (2015) Is moral beauty different from facial beauty? Evidence from an fMRI study. Soc Cogn Affect Neurosci 10: 814-823.

25. Preston SD, de Waal FB (2002) Empathy: Its ultimate and proximate bases. Behav Brain Sci 25: 1-20.

26. de Waal FBM, Preston SD (2017) Mammalian empathy: Behavioural manifestations and neural basis. Nat Rev Neurosci 18: 498-509.
27. Bancroft J (1995) The menstrual cycle and the well being of women. Soc Sci Med 41: 785-791.

28. Weisman O, Zagoory-Sharon O, Feldman R (2014) Oxytocin administration, salivary testosterone, and father-infant social behavior. Prog Neuropsychopharmacol Biol Psychiatry 49: 47-52.

29. Plymate SR, Tenover JS, Bremner WJ (1989) Circadian variation in testosterone, sexhormone-binding globulin, and calculated nonsex hormone-binding globulin boundtestosterone in healthy young and elderly men. J Androl 10: 366-371.

30. Kuzawa CW, Gettler LT, Muller MN, et al. (2009) Fatherhood, pair bonding and testosterone in the Philippines. Horm Behav 56: 429-435.

31. Sollberger S, Bernauer T, Ehlert U (2016) Salivary testosterone and cortisol are jointly related to pro-environmental behavior IN men. Soc Neurosci 11: 553-566. 